\title{
Clinical Study \\ Fecal Calprotectin and Clinical Disease Activity in Pediatric Ulcerative Colitis
}

\author{
Kaija-Leena Kolho' ${ }^{1}$ and Dan Turner ${ }^{2}$ \\ ${ }^{1}$ Children's Hospital, Helsinki University Central Hospital, P.O. Box 281, 00029 Helsinki, Finland \\ ${ }^{2}$ Pediatric Gastroenterology Unit, Shaare Zedek Medical Center, The Hebrew University of Jerusalem, \\ P.O. Box 3235, Jerusalem 91031, Israel
}

Correspondence should be addressed to Kaija-Leena Kolho; kaija-leena.kolho@helsinki.fi

Received 5 January 2013; Accepted 29 January 2013

Academic Editors: A. Amedei, A. W. Mangel, J. M. Pajares, L. Rodrigo, A. A. te Velde, and A. Weimann

Copyright $(2013$ K.-L. Kolho and D. Turner. This is an open access article distributed under the Creative Commons Attribution License, which permits unrestricted use, distribution, and reproduction in any medium, provided the original work is properly cited.

\begin{abstract}
Objective. To explore fecal calprotectin levels in pediatric ulcerative colitis (UC) in relation with the validated clinical activity index PUCAI. Methods. This study included all 37 children (median age 14 years) with UC who had calprotectin measured (PhiCal ELISA Test) by the time of PUCAI assessment at the Children's Hospital of Helsinki in a total of 62 visits. Calprotectin values $<100 \mu \mathrm{g} / \mathrm{g}$ of stool were considered as normal. The best cut-off value of each measure to predict 3-month clinical outcome was derived by maximizing sensitivity and specificity. Results. In clinically active disease (PUCAI $\geq 10$ ), calprotectin was elevated in 29/32 patients (91\% sensitivity). When in clinical remission, 26\% (8/30) of the children had normal calprotectin but 7 (23\%) had an exceedingly high level ( $>1000 \mu \mathrm{g} / \mathrm{g})$. The best cut-off value for calprotectin for predicting poor outcome was $800 \mu \mathrm{g} / \mathrm{g}$ (sensitivity $73 \%$, specificity $72 \%$; area under the ROC curve being 0.71 (95\%CI 0.57-0.85)) and for the PUCAI best cut-off values $>10$ (sensitivity $62 \%$, specificity 64\%; area under the ROC curve 0.714 (95\%CI 0.58-0.85)). Conclusion. The clinical relevance of somewhat elevated calprotectin during clinical remission in pediatric UC is not known and, until further evidence accumulates, does not indicate therapy escalation.
\end{abstract}

\section{Introduction}

Neutrophil-derived markers, such as fecal calprotectin or lactoferrin, have proven to correlate well with mucosal inflammation of ulcerative colitis (UC) at a rho range of $0.6-0.8[1-4]$. Fecal level of these markers reflects the mucosal influx of inflammatory cells in the gut. When the level of these markers is low, the presence of active inflammation in the colon is unlikely [3,5-8]. The probability of 1-year remission in UC children with normal calprotectin may be as high as $75 \%$ [9]. On the other hand, in UC (and unlike in Crohn's disease), clinical judgment of symptoms also correlates well with endoscopic appearance, at a range of rho 0.7-0.8 [10], and clinical assessment also predicts well clinical outcomes in both adult [11] and pediatric severe UC [12]. Recently, we showed that calprotectin levels rarely decline completely during therapy with glucocorticoids or TNF- $\alpha$-antagonist agents suggesting ongoing inflammation in the majority $[13,14]$.

The PUCAI is the validated pediatric ulcerative colitis activity index showing good correlation with endoscopic disease activity [15-17]. The index is based on item scores reflecting the clinical situation within the last two days and may thus be used in the acute setting [15]. In acute severe colitis, PUCAI reflects therapeutic response better than calprotectin, the levels of which do not change as rapidly along improvement as the PUCAI scores $[18,19]$. There are, however, limited data on the performance of fecal markers related to simple clinical assessment of pediatric UC in clinical practice. We aimed to explore calprotectin levels in relation to clinical disease activity assessed with the validated activity index PUCAI in pediatric UC.

\section{Subjects and Methods}

This retrospective study included all children with UC who had calprotectin measured and clinical data recorded for the assessment of the PUCAI at the Children's Hospital of Helsinki from December 2005 to January 2012, most samples being from the three recent years. Diagnosis of UC was based 
on typical clinical presentation as well as upper and lower endoscopy [20].

Clinical disease activity was scored using the PUCAI consisted that of six clinical items scored from 0 to 85 points (abdominal pain 0-10; rectal bleeding 0-30; stool consistency $0-10$; number of stools per 24 hours (0-15); nocturnal stools (0-10), and activity level (0-10)). Cut-off scores for remission (PUCAI < 10 points), mild (10-34), moderate (35-64)) and severe $(\geq 65)$ disease activity have been validated on three different cohorts with sensitivity and specificity of $>90 \%$ $[10,15,16]$.

Three-month clinical outcome was assessed using a physicians global assessment (PGA) from 0 (remission) to 3 (severe disease). Good outcome was defined as no need to change maintenance medication, successful weaning of steroids when applicable, and disease activity of no more than 1 according to PGA.

Children provided a stool sample within two days of the time of PUCAI assessment. The samples in children undergoing endoscopy were taken prior to bowel cleansing [21]. Fecal calprotectin was measured using the PhiCal ELISA Test (Nova Tec Immunodiagnostica, Dietzenbach, GmBH, Germany). Calprotectin value $<100 \mu \mathrm{g} / \mathrm{g}$ of stool was considered as normal whereas values $>1000 \mu \mathrm{g} / \mathrm{g}$ were considered as exceedingly high $[9,13,14]$.

2.1. Ethics. The patients involved in this study participated in a study on pediatric inflammatory bowel disease approved by the Ethics Committee of the Helsinki University Central Hospital. The patients/their guardians signed an informed consent form when entering the study.

2.2. Statistical Analyses. Data are presented as means ( \pm standard deviation) or medians (interquartile range) as appropriate for the distribution normality. Correlations between individual parameters were sought using Spearman correlation. To compare the predictive utility of the PUCAI as compared with calprotectin, area under the receiver operating characteristics (ROC) curve $( \pm 95 \%$ CI) was used. The best cut-off values of each measure to predict 3-month clinical outcome were derived by maximizing sensitivity and specificity. All analyses were performed using SPSS V16.

\section{Results}

A total of 62 visits were included from 37 different children with fecal calprotectin values available by the time of the assessment of the PUCAI ( 18 (49\%) males, median age 14.3 years (IQR 13.0-15.8, 33 (89\%) with extensive disease and the others with left-sided disease; Table 1). Fourteen (38\%) children were at disease onset and the others with median disease duration of 1.5 (IQR 0.7-3.0) years. Sixteen of the visits were during clinical remission (judged by PGA), 16 (26\%) during mild disease activity, 12 (19\%) during moderate disease activity, and 18 (29\%) during severe disease activity. Median number of samples per patient was 1 (IQR: 1-2, range $1-5)$.
TABLE 1: Background data of the 37 pediatric patients with ulcerative colitis.

\begin{tabular}{lc}
\hline Age (years) & 14 (median, range 4.5-17) \\
Gender & Male $n=18$ \\
Disease duration (years) & 1.5 (median, range 0-5) \\
Disease extension & Pancolitis $n=33$ \\
& Left-sided colitis $n=4$ \\
Medication & 5-ASA $n=13$ \\
5-ASA and/or azathioprine $n=5$ \\
Infliximab $n=8$ \\
Glucocorticoids $n=11$ \\
None $n=11$ \\
\hline
\end{tabular}

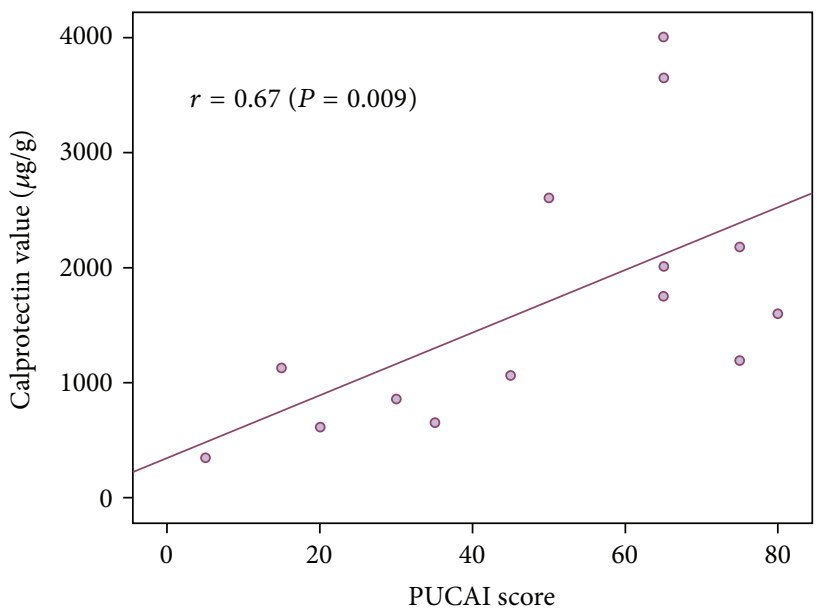

FIGURE 1: The Spearman correlation of the pediatric ulcerative activity index (PUCAI) and fecal calprotectin in pediatric patients with ulcerative colitis undergoing diagnostic endoscopy.

In the total sample set, the correlation of calprotectin and the PUCAI was good $(r=0.53, P<0.001, n=62)$. The correlation between PUCAI and calprotectin among the 14 children at diagnosis (all with clinically active disease) was higher $(r=0.67, P=0.009$; Figure 1$)$.

The best calprotectin cutoff to identify the $30 / 62$ visits in clinical remission was $<800 \mu \mathrm{g} / \mathrm{g}$ (sensitivity $73 \%$ and specificity $72 \%$; area under the ROC curve of 0.76 (95\% CI 0.63-0.88); Figure 2). The values were not different when considering only one observation per patient to avoid possible repeated measures bias (the first visit per patient; $n=37$ ) with an area under the ROC curve of $0.71(0.53-0.89)$ and similar cut-off value.

Calprotectin was exceedingly high in all 13 samples collected during a severe attack (i.e., PUCAI $\geq 65$ ) (median $2179 \mu \mathrm{g} / \mathrm{g}$ range 1190-9504 (IQR 1682-5310)). All those with PUCAI scores reflecting moderate-severe disease (40-85) had elevated calprotectin values. In mild-to-moderate disease (PUCAI 10-64, $n=19$ ) calprotectin was elevated in all except two patients (median $829 \mu \mathrm{g} / \mathrm{g}$, range 7-7287 (IQR 4161599)). Calprotectin was completely normal in 8 of 30 assessments performed during clinical remission (26\%). In seven 


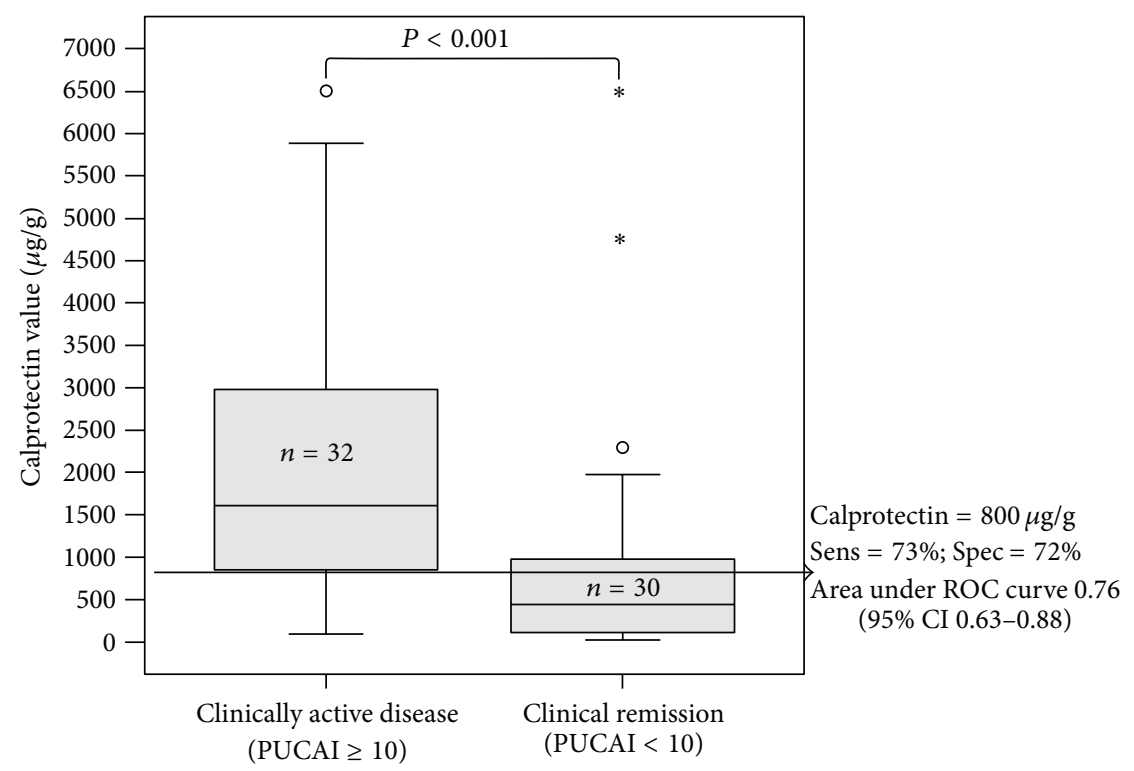

FIGURE 2: The relation of the pediatric ulcerative activity index (PUCAI) and fecal calprotectin in pediatric patients with ulcerative colitis. The arrow shows the best fecal calprotectin cutoff (by maximizing sensitivity and specificity) to identify patients in clinical remission according the PUCAI.

(23\%), calprotectin level was exceedingly high $(>1000 \mu \mathrm{g} / \mathrm{g})$. In four of these, the assessments were done on the day of maintenance infusion of infliximab, in two cases steroids had been tapered within one-to-two weeks earlier and, one was on only 5-ASA. Three of these seven (two on infliximab, one in whom steroids were tapered off) remained in sustainedsteroid-free clinical remission 3-months after the sample date, despite the very high calprotectin level.

The PUCAI performed just as well as calprotectin in predicting 3-month clinical outcome (poor versus good outcome), area under the ROC curve being 0.71 (95\% CI $0.57-0.85)$ versus 0.714 (95\% CI $0.58-0.85)$, respectively. The best cutoff for calprotectin for predicting poor outcome was $800 \mu \mathrm{g} / \mathrm{g}$ (sensitivity $73 \%$, specificity $72 \%$ ) and for the PUCAI best cut-off $>10$ (sensitivity $62 \%$, specificity $64 \%$ ).

Of the 30 assessments in clinical remission, 20 (66\%) remained in steroid-free clinical remission for the forthcoming three months. All 10 assessments of both clinical remission or mild clinical disease (i.e., PUCAI < 35), and normal calprotectin $<100$, remained in steroid-free remission in 3 months. The calprotectin values and outcome of the patients in remission or having mild-to-moderate disease activity according to the PUCAI during the following three months ara shown in Table 2.

\section{Discussion}

The use of calprotectin as a surrogate marker for intestinal inflammation is emerging. However, the data on calprotectin related to clinical disease activity in children with UC are sparse. We show good correlation between the PUCAI and fecal calprotectin. In the clinically severe disease (PUCAI > $65)$, calprotectin was exceedingly high $(>1000 \mu \mathrm{g} / \mathrm{g})$ in all cases and did not bring any additional information to clinical assessment. It is worthwhile noting that the PUCAI is much more responsive to a rapid change than calprotectin in severe disease; that is, the PUCAI shows a sharp decrease within only a few days of starting effective medication [18] reflecting the well-known notion that mucosal healing lags after clinical remission. On the other hand, some of those in clinical remission according to PUCAI still had elevated calprotectin levels, but in the majority the levels were only moderately elevated. Our data suggests, however, that closer monitoring should be offered to the patients in clinical remission but with exceedingly high calprotectin level since many of them may show deterioration within the forthcoming weeks. It may also suggest that the current therapies are unable to induce complete attenuation of mucosal inflammation in a large proportion of the pediatric patients. Recently, we showed that only one-third of 41 children with UC had normal calprotectin levels while $13 \%$ had exceedingly high levels despite all being in longstanding clinical remission defined using the PGA (i.e., $80 \%$ with at least 6 -month duration followup) [9].

Although mucosal healing has been shown in adults, to predict favourable clinical outcome in UC $[11,22,23]$ is yet to be proven that this is superior to clinical assessment of remission. Indeed, in the combined ACT cohorts (466 adults with UC treated with either infliximab or placebo) endoscopic healing after 8 weeks of therapy predicted 1-year colectomy overall but not among the subset of patients with clinical remission [22]. Moreover, clinical judgment of response to steroid treatment in acute severe UC has been shown to predict long-term, clinically important, outcomes, both in adults [11] and in children [12, 24], irrespective of endoscopic healing. Similarly here, we could not find any major difference between clinical (PUCAI) and endoscopic (calprotectin) assessment of disease activity with regards to predicting 3-month steroid free remission although the sensitivity 
TABLE 2: Three-month outcome of pediatric patients with mild-tomoderate ulcerative colitis according to the clinical disease activity index PUCAI and fecal calprotectin at baseline. The outcome was determined according to physicians global assessment.

\begin{tabular}{|c|c|c|c|}
\hline No. & $\begin{array}{c}\text { Disease activity } \\
\text { according to the PUCAI } \\
\text { (total score) }\end{array}$ & $\begin{array}{l}\text { Calprotectin } \\
\mu \mathrm{g} / \mathrm{g} \text { of stool }\end{array}$ & $\begin{array}{c}\text { Outcome within } 3 \\
\text { months }\end{array}$ \\
\hline 1 & Remission $(<10)$ & 14 & Remission \\
\hline 2 & & 14 & Remission \\
\hline 3 & & 16 & Remission* \\
\hline 4 & & 30 & Remission \\
\hline 5 & & 45 & Remission \\
\hline 6 & & 69 & Remission \\
\hline 7 & & 69 & Remission \\
\hline 8 & & 90 & Remission \\
\hline 9 & & 131 & Remission \\
\hline 10 & & 155 & $\begin{array}{c}\text { Flare (within two } \\
\text { months) }\end{array}$ \\
\hline 11 & & 189 & $\begin{array}{c}\text { Flare (when } \\
\text { tapering corticoid) }\end{array}$ \\
\hline 12 & & 333 & Remission* \\
\hline 13 & & 345 & Flare \\
\hline 14 & & 372 & Remission \\
\hline 15 & & 411 & Remission \\
\hline 16 & & 441 & Remission \\
\hline 17 & & 521 & Remission \\
\hline 18 & & 532 & $\begin{array}{c}\text { Flare (when } \\
\text { tapering corticoid) }\end{array}$ \\
\hline 19 & & 581 & Remission \\
\hline 20 & & 628 & Remission \\
\hline 21 & & 663 & $\begin{array}{l}\text { Flare (within a } \\
\text { month) }\end{array}$ \\
\hline 22 & & 796 & Remission \\
\hline 23 & & 902 & Flare ${ }^{*}$ \\
\hline 24 & & 1052 & Remission ${ }^{*}$ \\
\hline 25 & & 1173 & Flare ${ }^{*}$ \\
\hline 26 & & 1233 & Remission \\
\hline 27 & & 1976 & $\begin{array}{c}\text { Flare (when } \\
\text { tapering corticoid) }\end{array}$ \\
\hline 28 & & 2295 & Flare ${ }^{*}$ \\
\hline 29 & & 4518 & $\begin{array}{c}\text { Flare (within two } \\
\text { weeks) }\end{array}$ \\
\hline 30 & & 9625 & Remission \\
\hline 31 & $\begin{array}{l}\text { Mild-to-moderate } \\
\text { disease }(10-64)\end{array}$ & 7 & Remission \\
\hline 32 & & 55 & Remission \\
\hline 33 & & 87 & Remission \\
\hline 34 & & 327 & $\begin{array}{c}\text { Flare (when } \\
\text { tapering corticoid) }\end{array}$ \\
\hline 35 & & 416 & Remission \\
\hline
\end{tabular}

TABLE 2: Continued.

\begin{tabular}{lccc}
\hline $\begin{array}{c}\text { Disease activity } \\
\text { according to the PUCAI } \\
\text { (total score) }\end{array}$ & $\begin{array}{c}\text { Calprotectin } \\
\mu \mathrm{g} / \mathrm{g} \text { of stool }\end{array}$ & $\begin{array}{c}\text { Outcome within 3 } \\
\text { months }\end{array}$ \\
\hline 36 & 611 & Lost from followup \\
37 & 653 & Flare \\
38 & 751 & Flare \\
39 & 766 & Flare \\
40 & & 829 & Flare (ongoing) \\
41 & & 856 & Remission \\
42 & Mild-to-moderate & 1067 & Flare \\
43 & disease (10-34) & 1110 & Remission \\
44 & & 1127 & Remission \\
45 & 1599 & Flare (when tapering \\
& & 1667 & Flarticoid) \\
46 & 1911 & Flare (ongoing) \\
47 & 2604 & Flare \\
48 & 7287 & Flare (when tapering \\
49 & & & corticoid) \\
\hline$*$ & & &
\end{tabular}

${ }^{*}$ Sample taken on the day of infliximab administration.

and specificity of calprotectin were somewhat higher than the PUCAI. This should be interpreted with caution given the small sample size, the retrospective design, and the relatively short follow-up duration.

Notably, it remains an unanswered question whether immunosuppressive therapy should be escalated during clinical remission solely based on the presence of elevated calprotectin. The question is not merely if calprotectin levels during remission are independently predictive, but if the predictive power is large enough to justify the associated adverse events. In other words, how many children in remission will be required to step up from 5-ASA to thiopurines or even antiTNF in order to obtain one favourable outcome (i.e., number needed to treat). Currently, this cannot be recommended until evidence is available to show that this aggressive approach indeed leads to better outcomes.

Furthermore, the target level of fecal surrogate markers to define acceptable therapeutic response is not known. In a previous study, $89 \%$ of 25 young patients with Crohn's disease in clinical remission remained in remission for nine months if their fecal calprotectin level was lower than $400 \mu \mathrm{g} / \mathrm{g}$ [25]. Here, the best cutoff for calprotectin for predicting 3-month poor outcome was as high as $>800 \mu \mathrm{g} / \mathrm{g}$ and for the PUCAI scores $\geq 10$ (which is the PUCAI definition for active disease) with no major difference in sensitivity and specificity.

In conclusion, in pediatric UC, clinical disease activity assessed with the validated index PUCAI shows good correlation with the levels of calprotectin. At present, the clinical relevance of elevated calprotectin level when in sustained clinical remission is not known and, until known otherwise, does not indicate escalating therapy based on this isolated 
finding only. However, it may indicate closer monitoring, especially in those with values $>800 \mu \mathrm{g} / \mathrm{g}$.

\section{Acknowledgments}

The authors thank Ms. Anne Nikkonen for her excellent assistance in gathering the patient data. The study was supported by the Finnish Pediatric Research Foundation and the Helsinki University Central Hospital Research Fund. D. Turner declares receiving royalties from the Hospital for Sick Children. There is no conflict of financial interests.

\section{References}

[1] S. K. Bunn, W. M. Bisset, M. J. C. Main, and B. E. Golden, "Fecal calprotectin as a measure of disease activity in childhood inflammatory bowel disease," Journal of Pediatric Gastroenterology and Nutrition, vol. 32, no. 2, pp. 171-177, 2001.

[2] S. K. Bunn, W. M. Bisset, M. J. C. Main, E. S. Gray, S. Olson, and B. E. Golden, "Fecal calprotectin: validation as a noninvasive measure of bowel inflammation in childhood inflammatory bowel disease," Journal of Pediatric Gastroenterology and Nutrition, vol. 33, no. 1, pp. 14-22, 2001.

[3] R. B. Canani, G. Terrin, L. Rapacciuolo et al., "Faecal calprotectin as reliable non-invasive marker to assess the severity of mucosal inflammation in children with inflammatory bowel disease," Digestive and Liver Disease, vol. 40, no. 7, pp. 547-553, 2008.

[4] A. Diamanti, F. Colistro, M. S. Basso et al., "Clinical role of calprotectin assay in determining histological relapses in children affected by inflammatory bowel diseases," Inflammatory Bowel Diseases, vol. 14, no. 9, pp. 1229-1235, 2008.

[5] R. B. Canani, L. Rapacciuolo, M. T. Romano et al., "Diagnostic value of faecal calprotectin in paediatric gastroenterology clinical practice," Digestive and Liver Disease, vol. 36, no. 7, pp. 467470, 2004.

[6] T. R. Walker, M. L. Land, A. Kartashov et al., "Fecal lactoferrin is a sensitive and specific marker of disease activity in children and young adults with inflammatory bowel disease," Journal of Pediatric Gastroenterology and Nutrition, vol. 44, no. 4, pp. 414422, 2007.

[7] T. Aomatsu, A. Yoden, K. Matsumoto et al., "Fecal calprotectin is a useful marker for disease activity in pediatric patients with inflammatory bowel disease," Digestive Diseases and Sciences, vol. 56, no. 8, pp. 2372-2377, 2011.

[8] P. Henderson, A. Casey, S. J. Lawrence et al., "The diagnostic accuracy of fecal calprotectin during the investigation of suspected pediatric inflammatory bowel disease," The American Journal of Gastroenterology, vol. 107, no. 6, pp. 941-949, 2012.

[9] T. Sipponen and K. L. Kolho, "Faecal calprotectin in children with clinically quiescent inflammatory bowel disease," Scandinavian Journal of Gastroenterology, vol. 45, no. 7-8, pp. 872-877, 2010.

[10] D. Turner, C. H. Seow, G. R. Greenberg, A. M. Griffiths, M. S. Silverberg, and A. H. Steinhart, "A systematic prospective comparison of noninvasive disease activity indices in ulcerative colitis," Clinical Gastroenterology and Hepatology, vol. 7, no. 10, pp. 1081-1088, 2009.

[11] A. Gustavsson, G. Järnerot, E. Hertervig et al., "Clinical trial: colectomy after rescue therapy in ulcerative colitis-3-year follow-up of the Swedish-Danish controlled infliximab study,"
Alimentary Pharmacology and Therapeutics, vol. 32, no. 8, pp. 984-989, 2010.

[12] D. Turner, D. Mack, N. Leleiko et al., "Severe pediatric ulcerative colitis: a prospective multicenter study of outcomes and predictors of response," Gastroenterology, vol. 138, no. 7, pp. 2282-2291, 2010.

[13] K. L. Kolho, T. Raivio, H. Lindahl, and E. Savilahti, "Fecal calprotectin remains high during glucocorticoid therapy in children with inflammatory bowel disease," Scandinavian Journal of Gastroenterology, vol. 41, no. 6, pp. 720-725, 2006.

[14] A. Hämäläinen, T. Sipponen, and K.-L. Kolho, "Infliximab in pediatric inflammatory bowel disease rapidly decreases fecal calprotectin levels," World Journal of Gastroenterology, vol. 17, pp. 5166-5171, 2011.

[15] D. Turner, A. R. Otley, D. Mack et al., "Development, validation, and evaluation of a pediatric ulcerative colitis activity index: a prospective multicenter study," Gastroenterology, vol. 133, no. 2, pp. 423-432, 2007.

[16] D. Turner, J. Hyams, J. Markowitz et al., "Appraisal of the pediatric ulcerative colitis activity index (PUCAI)," Inflammatory Bowel Diseases, vol. 15, no. 8, pp. 1218-1223, 2009.

[17] D. Turner, C. H. Seow, G. R. Greenberg, A. M. Griffiths, M. S. Silverberg, and A. H. Steinhart, "A systematic prospective comparison of noninvasive disease activity indices in ulcerative colitis," Clinical Gastroenterology and Hepatology, vol. 7, no. 10, pp. 1081-1088, 2009.

[18] D. Turner, S. T. Leach, D. Mack et al., "Faecal calprotectin, lactoferrin, M2-pyruvate kinase and S100A12 in severe ulcerative colitis: a prospective multicentre comparison of predicting outcomes and monitoring response," Gut, vol. 59, no. 9, pp. 1207-1212, 2010.

[19] G. T. Ho, H. M. Lee, G. Brydon et al., "Fecal calprotectin predicts the clinical course of acute severe ulcerative colitis," American Journal of Gastroenterology, vol. 104, no. 3, pp. 673-678, 2009.

[20] J. E. Lennard-Jones, "Classification of inflammatory bowel disease," Scandinavian Journal of Gastroenterology, Supplement, vol. 24, no. 170, pp. 2-6, 1989.

[21] K. L. Kolho, H. Alfthan, and E. Hämäläinen, "Effect of bowel cleansing for colonoscopy on fecal calprotectin levels in pediatric patients," Journal of Pediatric Gastroenterology and Nutrition, vol. 55, no. 6, pp. 751-753, 2012.

[22] J. F. Colombel, P. Rutgeerts, W. Reinisch et al., "Early mucosal healing with infliximab is associated with improved long-term clinical outcomes in ulcerative colitis," Gastroenterology, vol. 141, no. 4, pp. 1194-1201, 2011.

[23] K. F. Frøslie, J. Jahnsen, B. A. Moum, and M. H. Vatn, "Mucosal healing in inflammatory bowel disease: results from a Norwegian population-based cohort," Gastroenterology, vol. 133, no. 2, pp. 412-422, 2007.

[24] D. Turner, C. M. Walsh, E. I. Benchimol et al., "Severe paediatric ulcerative colitis: incidence, outcomes and optimal timing for second-line therapy," Gut, vol. 57, no. 3, pp. 331-338, 2008.

[25] R. Shaoul, M. Sladek, D. Turner et al., "Limitations of fecal calprotectin at diagnosis in untreated pediatric Crohn's disease," Inflammatory Bowel Diseases, vol. 18, no. 8, pp. 1493-1497, 2012. 


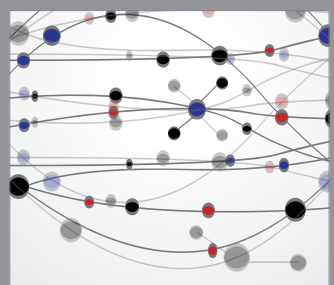

The Scientific World Journal
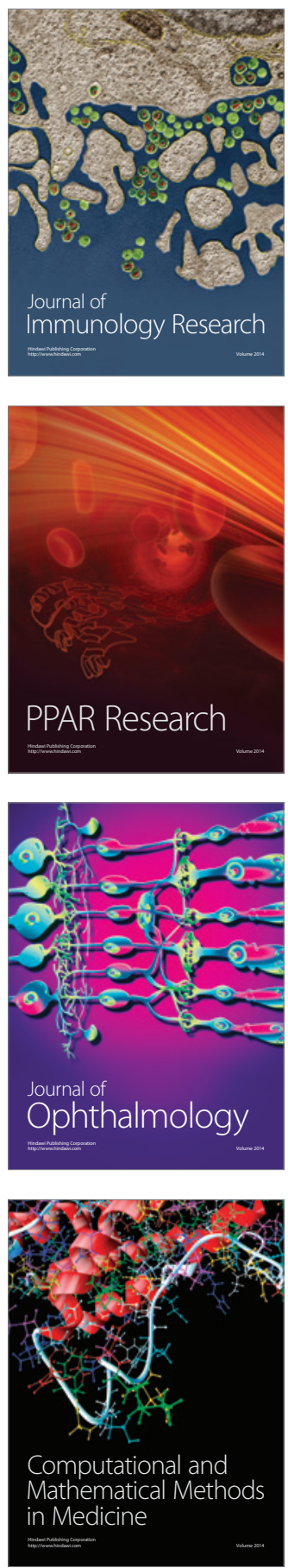

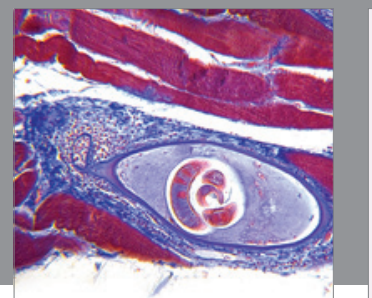

Gastroenterology

Research and Practice
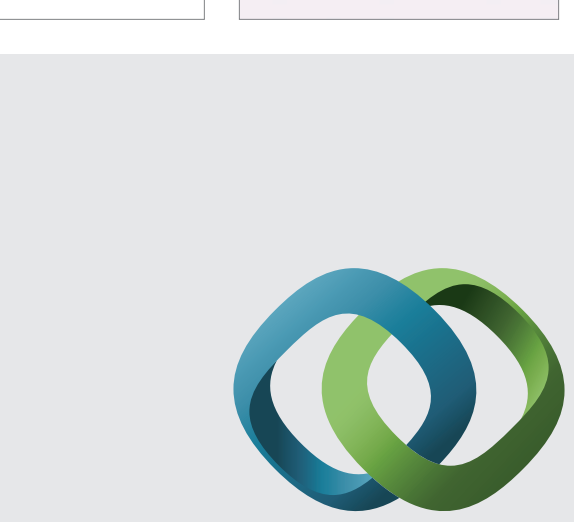

\section{Hindawi}

Submit your manuscripts at

http://www.hindawi.com
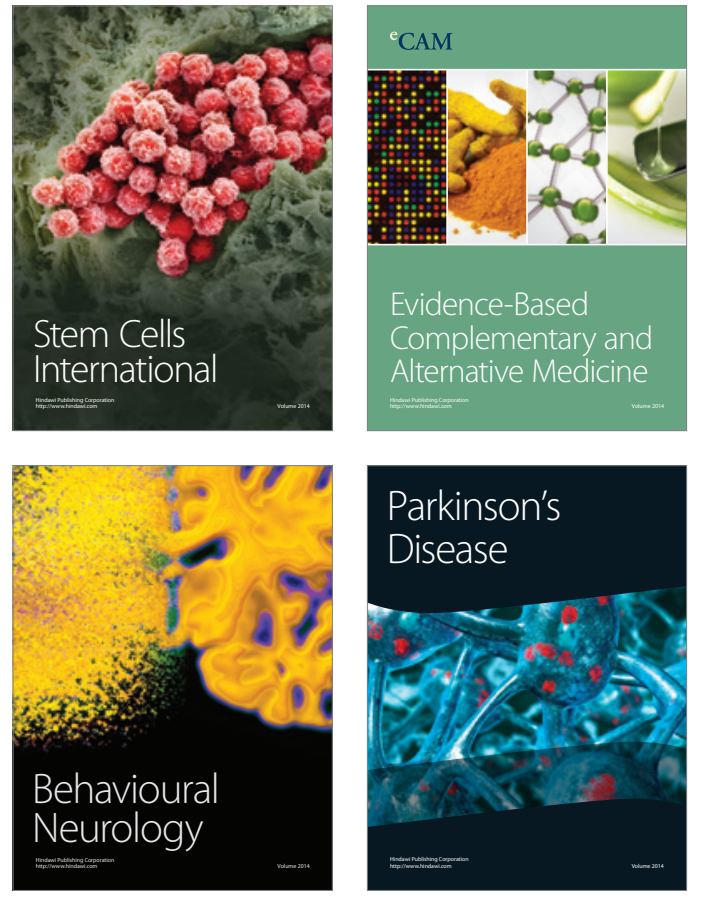
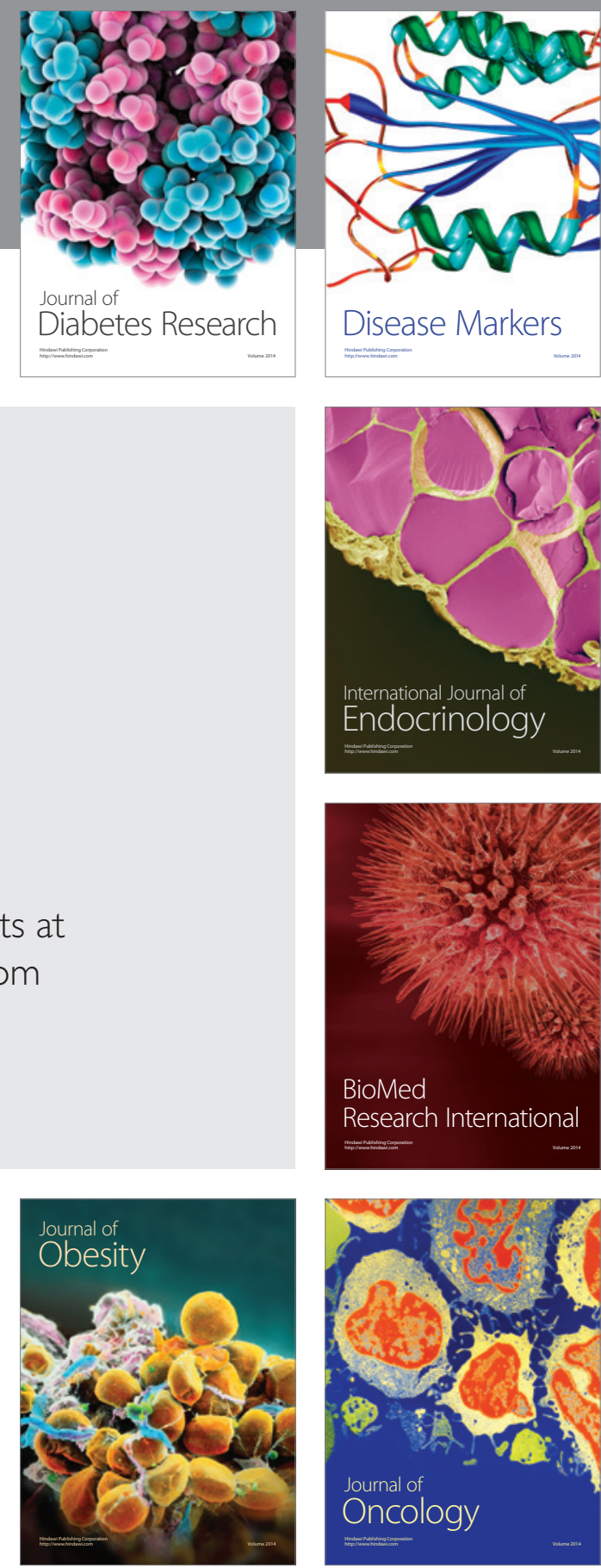

Disease Markers
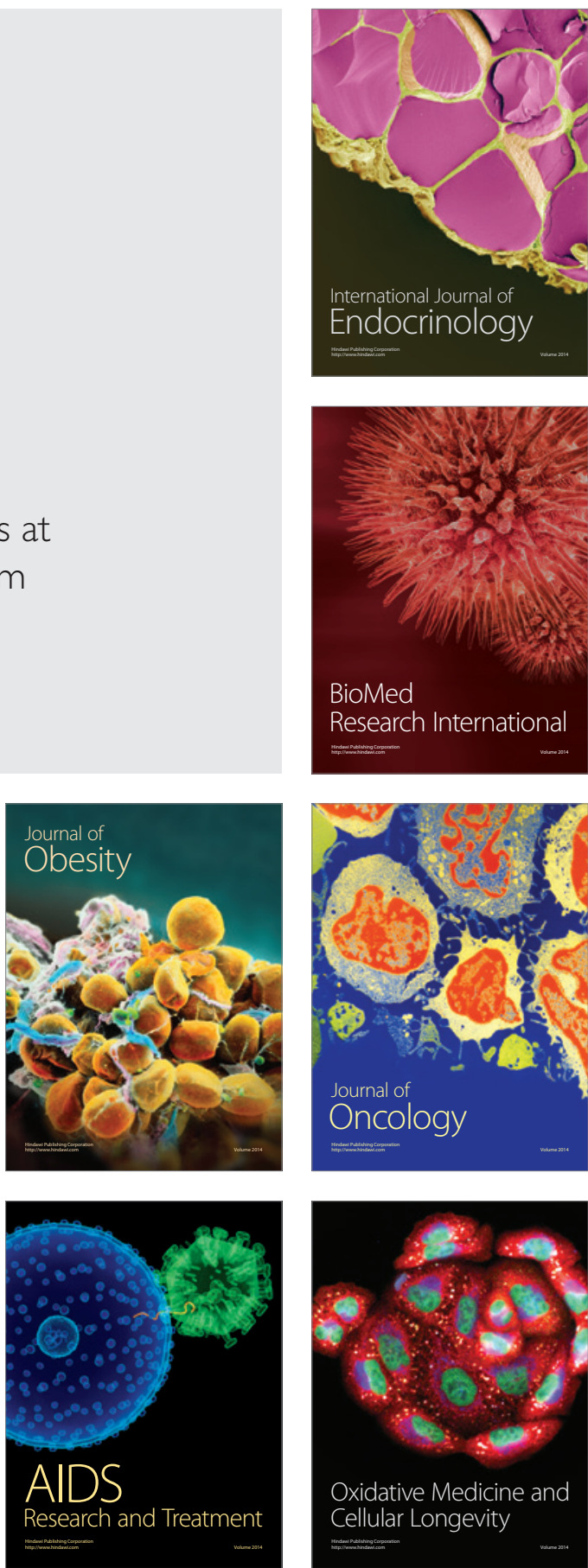